\title{
Runway behavior of Siamese fighting fish, Betta splendens, for aggressive display and food reinforcement
}

\author{
R. JEAN BOLS and JERRY A. HOGAN \\ University of Toronto, Toronto, M5S 1 Al Canada
}

\begin{abstract}
Fish were allowed to choose, in a T-maze, between various combinations of goalboxes containing either food or a mirror, or nothing. Only food and a mirror maintained swimming, but percent choice and speed were higher for food than for a mirror. Measures of time motionless in the runway, turning away from the goalbox, and air gulping supported the notion that a stimulus for aggressive display induces avoidance as well as approach tendencies and that the aversive component in the display situation is responsible for poorer performance for a mirror.
\end{abstract}

Male Siamese fighting fish, Betta splendens, perform an elaborate aggressive display that is reliably evoked by the sight of a male Betta, a model of a male Betta, or the fish's mirror image. Simpson (1968) provides a detailed description of the behavior. It is well documented that the opportunity to view display-evoking stimuli is positively reinforcing (see Hogan \& Roper, 1978, for a review). Nonetheless, studies comparing aggressive display and food reinforcement in $B$. splendens have shown differential effects on performance in a number of ways: When reinforced with the opportunity to display, fish show (a) lower asymptotic response levels, (b) more variable performance, (c) more rapid extinction, and (d) a failure to adjust response rates to ratio requirements (Hogan, 1967; Hogan, Kleist, \& Hutchings, 1970). There is no clear explanation for these differences.

One explanation that could account for some of these differences is that aggressive display may possess negative as well as positive reinforcing properties, and performance for display would be determined by some combination of these two effects. Aggressive displays, in many species, have been shown to be motivated by both approach tendencies (aggression) and avoidance tendencies (escape or fear) (Hinde, 1970; Morris, 1956; Tinbergen, 1952). In Bettas, there is considerable evidence that a stimulus for aggressive display induces avoidance as well as

This study was based on a dissertation submitted in partial fulfillment of the requirements for a $\mathrm{PhD}$ degree at the University of Toronto by R. J. Bols. It was supported by Grant A-0140 from the National Research Council of Canada. We thank Arturo Bouzas, Karen Hollis, Sara Shettleworth, and Gary Walters for their helpful criticisms of the manuscript. Don MacNaughton assisted with computer analysis. Requests for reprints should be sent to J.A. Hogan, Department of Psychology, University of Toronto, Toronto, Ontario M5S 1 A1 Canada. approach tendencies. For example, experiments by Baenninger (1970) and Rhoad, Kalat, and Klopfer (1975) show that Bettas will work to avoid as well as to approach a mirror, model, or a live conspecific under certain conditions.

Further support for the idea that display-evoking stimuli induce avoidance as well as approach comes from experiments by Bols (1977). She gave Bettas a choice between an empty goalbox and a goalbox with a display-evoking stimulus behind a clear partition. Three display-evoking stimuli were tested: a live displaying male Betta, a live male paradise fish (Macropodus opercularis), and a live nondisplaying male Betta. All three stimuli supported swimming down the runway, but the swimming speed was fastest for the displaying Betta, slower for the paradise fish, and slower still for the nondisplaying Betta. The percent choice for the goalbox with the stimulus was also highest for the displaying Betta (about 80\%), less for the paradise fish (about 50\%), and least for the nondisplaying Betta (only 20\%). Of particular interest is the fact that there was a negative correlation between percent choice and several measures of avoidance, including remaining motionless in the runway, turning away from the goalbox, and actual attempts to escape from the goalbox (thrashing) as well as the irrelevant activity of air gulping. These results all suggest that stimuli that evoke aggressive display and support instrumental performance in a runway also evoke avoidance behavior to various degrees. Thus, when comparing food and aggressive display as reinforcers, slower swimming for the sight of a conspecific could mean that food induces less avoidance than a display-evoking stimulus.

The purpose of the present experiment was to provide evidence for the above suggestion. Hogan et al. (1970) suggested that more detailed observation of the fishes' behavior in each reinforcement situation 
might provide such evidence. As we have seen above, Bols (1977) has made detailed observations in a display reinforcement situation, but similar data are not available from both food and display reinforcement situations under the same conditions. In this paper, we report the results of an experiment designed to allow a direct comparison of behavior to different reinforcers. Fish were given a choice of food vs. a mirror, food vs. an empty compartment, a mirror vs. an empty compartment, or two empty compartments. The group with a choice between two empty goal compartments was included to allow a comparison of performance for no reinforcer at all. Such a group has not been included in any of the previous runway studies.

\section{METHOD}

\section{Subjects}

Experimentally naive adult male Betta splendens obtained from a local supplier served as subjects. They were not selected randomly; rather, fish were initially run through a standard screening test in order to eliminate those that, on the basis of the experimenter's previous experience, would have a high probability of freezing in the test apparatus. This test included rating ease of capture in a net and measuring movement in an apparatus similar to the test apparatus. Readiness to display aggressively was not one of the criteria for selection. About $17 \%$ of the original total were thus eliminated. The 48 fish chosen for further testing were assigned randomly to the four experimental groups, 12 fish in each. Fish were maintained in the laboratory in 3.8-liter glass jars for a minimum of 2 weeks prior to testing. Daily feedings consisted of dry TetraMin and chopped raw chicken liver. During the preexperimental period, the subjects were kept isolated from other fish except for $10 \mathrm{~min}$ per week visual access to conspecifics. A light/dark cycle $(12 \mathrm{~h}: 12 \mathrm{~h})$ was in effect at all times, and water temperature was held at about $27^{\circ} \mathrm{C}$.

\section{Apparatus}

The apparatus consisted of a white runway, $50 \times 10 \times 11 \mathrm{~cm}$, which opened at each end into a transparent box that was $20 \mathrm{~cm}$ wide and $8 \mathrm{~cm}$ long. A removable black partition divided the endbox into two equal-sized compartments. At each end of the runway, a black door with adjacent $2.5-\mathrm{cm}$ holes permitted entry into either of the two compartments, and a white solid door could be lowered behind the black door to prevent exit. The entire apparatus was submerged to a depth of about $8 \mathrm{~cm}$ in a polyethylene-lined plywood box filled with water. The floor of the runway was covered with aquarium gravel. There were four such apparatuses (see Bols, 1977, for an illustration).

\section{Procedure}

The experimental design involved four major treatment groups given different reward choices in the two end compartments. These choices were between food and a mirror (F-M), food and an empty compartment, i.e., nothing (F-N), a mirror and an empty compartment (M-N), and two empty compartments $(\mathrm{N}-\mathrm{N})$. Food reinforcement on any trial consisted of a small piece of raw chicken liver delivered by hand through a dropper. Mirror reinforcement consisted of $20 \mathrm{sec}$ presentation of a mirror placed behind one wall of the endbox. Confinement period in the goal compartment was always $20 \mathrm{sec}$ before removal of the partition, regardless of type of reward, if any. Position of various rewards (right or left) was balanced between subjects within each group but remained constant for any given subject. In addition, half the subjects from each group were placed in the apparatus 2 days prior to testing and lived there for the duration of the experiment (familiar condition); the other half lived in their jars in the fish colony room except for actual test sessions (unfamiliar condition). Before placing each new batch of fish in the runways, the water was changed and the gravel thoroughly rinsed, because previous studies have shown that chemical stimuli from one fish can inhibit aggressive display in another (Ingersoll, Bronstein, \& Bonventre, 1976; but see also Dore, Lefebvre, \& Ducharme, 1978).

At the start of each session, fish were netted and placed in the startbox for $15 \mathrm{~min}$. The first trial began when the door was raised, and terminated when the fish entered one of the two compartments at the opposite end of the runway. After entry, the white door was lowered behind the fish. If a fish failed to leave the startbox within $120 \mathrm{sec}$, it was gently pushed with a piece of plastic. A maximum of $90 \mathrm{sec}$ in the runway was allowed before the fish was forced in a similar manner to enter a goal compartment. After $20 \mathrm{sec}$, the partition and black door were removed and placed appropriately in the opposite endbox, thereby converting the former goalbox into a startbox so the fish would be swimming in the opposite direction on the next trial.

Each session consisted of 10 trials. Two sessions per day separated by an interval of about $4 \mathrm{~h}$ were conducted for a total of nine sessions. Fish were tested in batches of four per week (one from each choice condition). The intertrial interval varied according to individual fishes' latencies, as fish within a batch were tested sequentially on each trial. The average intertrial interval was about 7 min (range 5-10 min). After each session, the fish were detained in the runway in order to equate food and mirror experience for all fish. This procedure involved giving them the appropriate amount of each reward to add up to the maximum possible, i.e., 10 pieces of liver and $200 \mathrm{sec}$ of mirror exposure.

Observations were recorded by depressing buttons on a keyboard that were connected to counters. The number of 1 -sec intervals in which an activity occurred provided a measure of its total duration. Frequencies were obtained simultaneously from a 20-pen Esterline-Angus event recorder. The following measures were recorded on each trial: (a) choice, (b) startbox latency, (c) runway time, (d) time motionless in the startbox and runway, (e) number of $180^{\circ}$ turns in the runway (a second turn was scored only after the fish resumed its original position facing the goalbox), and ( $f$ ) number of air gulps in the startbox and runway. This behavior consists of rising to the surface and taking in air through the mouth. Air thus obtained is passed through an accessory breathing apparatus located in the head and expelled through the mouth or opercula. For fish that chose the mirror, the duration of gill cover erection (a prominent component of display) was also recorded.

\section{Data Analysis}

Measures a through $f$ were subjected to three levels of analysis of variance. First a main overall analysis was performed which took into account all levels of the between-subjects factors (choice and familiarity) as well as the within-subject factor sessions. Subsidiary analyses were then made for each of the following a priori pairwise comparisons: F-M vs. F-N, F-M vs. $\mathrm{M}-\mathrm{N}, \mathrm{F}-\mathrm{N}$ vs. $\mathrm{M}-\mathrm{N}$, and $M-N$ vs. N-N. A further breakdown was carried out to analyze the sessions variable within each group. In all cases where subsidiary analyses were performed, significant $(p<.10)$ main effects or relevant interactions had been obtained in the overall analysis. Startbox latency, runway time, and time motionless were transformed to logarithms prior to analysis to correct for heterogeneity of variance. This transformation was selected according to a procedure given by Kirk (1968, pp. 66-67).

\section{RESULTS}

Under the conditions of the present experiment, asymptotic levels of performance were reached by about the fifth session for all groups. At asymptote, 


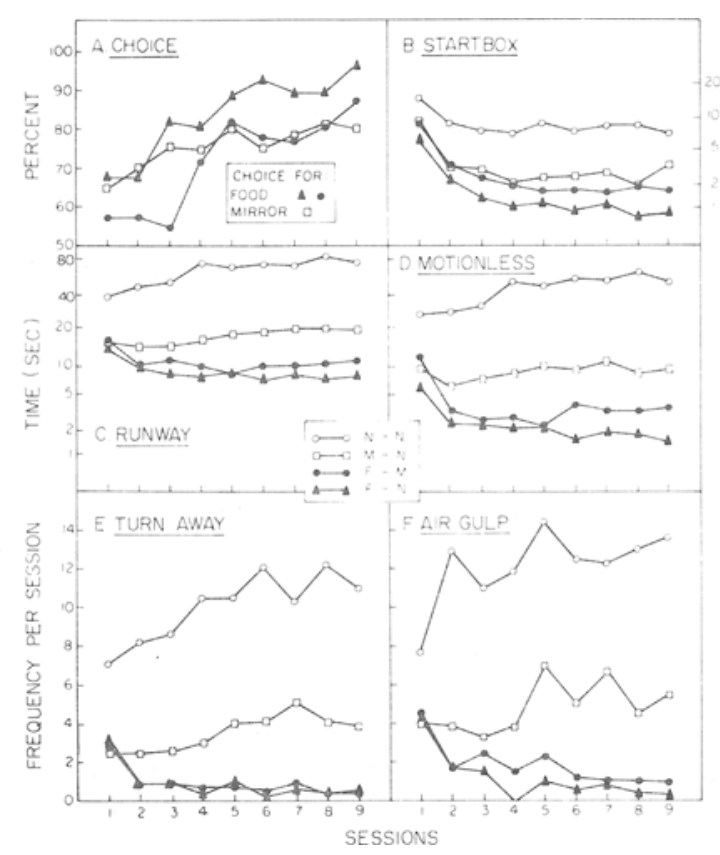

Figure 1. Measures of performance for the four experimental groups $(M=$ mirror; $F=$ food; $N=$ nothing) as a function of sessions (each session consisted of $\mathbf{1 0}$ trials).

Bettas preferred food to a mirror when given a choice, and food maintained performance at higher levels as measured by percent choice, startbox latency, and runway time. However, fish preferred a mirror to an empty compartment and runway swimming was not maintained in the absence of a specific goal object. Levels of air gulping and turning away from the goalbox were higher with mirror reinforcement than with food, and fish in the N-N condition also showed a high frequency of these behaviors. The data are presented in Figure 1, and the main results of the statistical analyses are presented in Table 1.

The effect of familiarity on choice behavior was small and nowhere near significant, though the direction of change was similar to that reported by Hogan (1974). Fish evinced a definite preference for food over display in both the familiar $(75 \%)$ choice) and unfamiliar $(69 \%$ choice) conditions. The only two measures to be significantly affected by familiarity were startbox latency and time motionless. Fish in the unfamiliar condition had longer latencies $[F(1,40)$ $=12.0, \mathrm{p}<.01]$ and spent more time motionless $[F(1,40)=4.77, p<.05]$ than in the familiar condition. Because the effects of familiarity on all other dependent measures were nonsignificant $(p>.10)$, results will not be presented. However, because familiarity was a variable in the procedure, it is included as a factor in all data analysis.

\section{Choice Behavior}

The percentage of trials on which the food or mir- ror goal compartment was chosen is presented in Figure 1A. (There are, of course, no choice results for the N-N group.) Fish in F-N chose food more often than fish in F-M, with asymptotic levels of choice for food at $90 \%$ and $80 \%$, respectively; but this difference was only marginally significant. F-N fish also chose food with a greater frequency than $\mathrm{M}-\mathrm{N}$ fish chose the mirror; asymptotic choice for mirror was about $80 \%$.

\section{Startbox Latency and Runway Time}

These results are presented in Figures $1 B$ and $1 C$. For both measures, times were shortest for fish in F-N, followed by F-M, M-N, and finally N-N. Both measures were also calculated separately for the food trials and the mirror trials in the F-M group: average times were essentially identical. All groups, with the exception of N-N, exhibited decreasing startbox latencies over sessions, while runway times decreased only for the two food groups. Runway times for the $\mathrm{N}-\mathrm{N}$ fish actually increased over sessions. In fact, after the first three sessions, most fish in $\mathrm{N}-\mathrm{N}$ needed to be forced into the goalbox on most trials.

\section{Time Motionless}

Figure 1D presents the duration motionless in the startbox and runway. The ordering of the four groups was similar to that for runway time and startbox latency, and the pattern of changes over sessions was essentially identical to that for runway time.

Remaining still is often taken to indicate the presence of fear motivation, but a relative measure such as proportion of time motionless is easier to interpret than a measure of absolute time. This measure was calculated for each fish for each of the last five

Table 1

Level of Significance Attained by Various Comparisons of Data in Figure 1

\begin{tabular}{|c|c|c|c|c|c|c|}
\hline & \multicolumn{6}{|c|}{ Measure } \\
\hline & Choice & $\begin{array}{c}\text { Start- } \\
\text { box }\end{array}$ & $\begin{array}{l}\text { Run- } \\
\text { way }\end{array}$ & $\begin{array}{c}\text { Motion- } \\
\text { less }\end{array}$ & $\begin{array}{l}\text { Turn } \\
\text { Away }\end{array}$ & $\begin{array}{l}\text { Air } \\
\text { Gulp }\end{array}$ \\
\hline & \multicolumn{6}{|c|}{ Groups $(\mathrm{df}=1,20)$} \\
\hline $\mathrm{F}-\mathrm{N}$ vs. F-M & .10 & .05 & .10 & .10 & n.s. & n.s. \\
\hline F-M vs. $\mathrm{M}-\mathrm{N}$ & n.s. & n.s. & .05 & .01 & .01 & .01 \\
\hline $\mathrm{F}-\mathrm{N}$ vs. $\mathrm{M}-\mathrm{N}$ & .05 & .01 & .01 & .05 & .01 & .01 \\
\hline \multirow[t]{2}{*}{$\mathrm{M}-\mathrm{N}$ vs. $\mathrm{N}-\mathrm{N}$} & * & .01 & .01 & .01 & .01 & .01 \\
\hline & \multicolumn{6}{|c|}{ Sessions $(\mathrm{df}=8,80)$} \\
\hline $\mathrm{F} \cdot \mathrm{N}$ & .01 & .01 & .01 & .01 & .01 & .01 \\
\hline $\mathrm{F}-\mathrm{M}$ & .01 & .01 & .01 & .01 & .01 & .01 \\
\hline $\mathrm{M}-\mathrm{N}$ & n.s. & .01 & n.s. & n.s. & n.s. & .05 \\
\hline $\mathrm{N}-\mathrm{N}$ & $*$ & n.s. & .01 & .01 & .05 & .01 \\
\hline
\end{tabular}

Note-For each significant comparison, $p<$ the level listed. Familiarity vs. unfamiliarity was included as a between-groups factor in these analyses (see text), so that total $d f=23$ for comparisons of groups and total $d f=107$ for comparisons of sessions. $\quad$ *Not tested. 
sessions. The mean proportion of time motionless for F-N was $23 \%$, for F-M was $30 \%$, for $\mathrm{M}-\mathrm{N}$ was $43 \%$, and for $\mathrm{N}-\mathrm{N}$ was $63 \%$. The food groups did not differ significantly from each other, but all other differences among groups were significant.

\section{Turning Away and Air Gulps}

The mean total frequency per session of turning away from the goalbox is presented in Figure $1 \mathrm{E}$, and Figure 1F shows the mean total number of air gulps that occurred in both startbox and runway in each session. F-N and F-M showed a very low frequency of turning and air gulping and did not differ from each other. The average terminal frequency for $\mathrm{M}-\mathrm{N}$ was about four turns and five air gulps and for $\mathrm{N}-\mathrm{N}$ was about 11 turns and 13 air gulps per session. Both behaviors decreased over sessions for the two food groups and increased over sessions in the other two groups. The increase in turning away over sessions for M-N, however, was not significant.

Interpretation of these results is complicated by the fact that differences between groups in turning away and air gulping parallel differences in startbox and runway times. It is possible that the increased frequency of these activities merely reflects the increased time available for them to occur. For this reason, the frequency of both responses per minute available time was calculated for each subject for each of the last five sessions. The mean frequency of both responses was about $.3 / \mathrm{min}$ in the two food groups (which did not differ significantly from each other) and about $1.0 / \mathrm{min}$ in the $\mathrm{M}-\mathrm{N}$ and $\mathrm{N}-\mathrm{N}$ groups (which also did not differ significantly from each other). The difference between the food groups and the other two groups, however, was highly significant.

The similarity in the pattern of results for turning away and air gulping suggests that the two behaviors are highly correlated, and the computed correlation using subject mean frequency per session was +.67 $(p<.01)$. It was often noted during the test trials for $\mathrm{M}-\mathrm{N}$ fish that air gulping often immediately preceded turning away: A fish would swim down the runway, pause in front of the goalbox, air gulp, and turn away. On other occasions, a fish would show the same sequence of behaviors, except it would enter the goalbox and display rather than turn away.

\section{Gill Cover Erection}

Sufficient data on duration of gill cover erection in the goalbox are available only for M-N fish. Mean duration declined significantly over the nine sessions from about $42 \%$ of the time in the first session to about $28 \%$ of the time in the last five sessions $[F(8,80)$ $=4.73, \mathrm{p}<.01]$. All fish displayed consistently in Session 1, but four fish failed to show reliable gill cover erection by Session 9. However, even these fish displayed on some trials of every session.

\section{DISCUSSION}

There are two general types of explanation one could propose for variations in swimming speed in a runway. The first type is in terms of the attractiveness of the goal object, with more attractive objects supporting faster swimming. Attractiveness could be determined by some inherent property of the goal object or by the level of motivation for a particular object. For example, it has been demonstrated that rats run faster for a preferred food, such as sugar, than for a less preferred food, such as casein (Young, 1948); they run faster for larger than for smaller amounts of food (Crespi, 1942); and they run faster when more hungry than when less hungry (Cotton, 1953). When comparing food and aggressive display as reinforcers for Bettas, faster swimming for food could mean that food is inherently more attractive than the sight of a conspecific and/or that, under the experimental conditions, hunger is stronger than aggression. If evidence for inherent differences could be found, one might wish to say that aggressive display is a weaker reinforcer than food.

A second type of explanation that could account for variations in swimming speed is in terms of properties of the goal object that induce avoidance or in some other way interrupt or interfere with approach to the goal. If the attractiveness of the goal object remains constant, faster swimming would indicate an object that induces less avoidance or interference. For example, it has been demonstrated that rats run slower and show more hesitation in the runway and engage in more irrelevant activities such as grooming when they receive an electric shock as well as food in the goalbox (Miller, 1959).

The results of the present experiment provide several kinds of evidence for the second type of explanation: that is, that poorer runway performance for display reinforcement is due to an aversive component in the reinforcing situation. The strongest evidence for this conclusion is that the occurrence of turning away from the goalbox, remaining motionless, and air gulping were relatively much higher in the M-N group than in either of the two food groups. As mentioned above, these behaviors have all been shown to be highly correlated with avoidance of (i.e., not choosing) the goal object under similar experimental conditions (Bols, 1977). The implication of this result is that the occurrence of escape behaviors is one cause for the longer runway times. Of course, these results do not exclude the possibility that inherent differences between reinforcers or motivational level are responsible for differences in runway times as well.

A second reason for postulating an aversive component in the display situation derives from the results of the F-M group. Despite the fact that this group 
chose food on $80 \%$ of the trials, the presence of the mirror in the other compartment tended to increase startbox latencies, runway times, and immobility relative to $\mathrm{F}-\mathrm{N}$. If the mirror was merely less attractive than food, one would not expect its occasional presence to interfere with performance for food.

Finally, the more frequent occurrence per unit of time of air gulping in the $\mathrm{M}-\mathrm{N}$ group suggests that it has causal factors additional to those associated with normal breathing. One attractive hypothesis is that air gulping under some circumstances is a displacement activity, that is, the increased frequency is caused by the presence of two conflicting tendencies (Hinde, 1970; Sevenster, 1961). In the case of the $\mathrm{M}-\mathrm{N}$ fish, the conflict would be between the positive (aggressive) and negative (escape) aspects of the display situation. The observed behavior of the fish in the maze certainly supports such a hypothesis.

Three further points deserve comment. First, it is worth noting that fish in the F-N group occasionally turned away from the goalbox and continued to choose the empty compartment on $10 \%$ of the trials. These results may mean that the fish have not yet learned the task completely and are still making occasional "mistakes." An intriguing alternative hypothesis is that some aspect of the food reinforcement situation may be aversive. Such an interpretation leads to the conclusion that differences among reinforcers may all be quantitative in nature, but that quantitative variations occur on more than one dimension. Still another interpretation is that some other motivation such as curiosity may occasionally become stronger than hunger and attract the fish to the empty compartment. This interpretation seems unlikely, however, in view of the results for fish in the $\mathrm{N}-\mathrm{N}$ group. Those results raise the second point for comment.

It is clear that an empty goalbox is not a neutral situation for a Betta. Runway times for the N-N fish showed a large and significant increase over sessions, and the occurrence of escape was relatively much higher than in the food conditions and approximated that in the $\mathrm{M}-\mathrm{N}$ condition. It seems likely that the aversiveness of the empty goalbox is related to the procedure of gently pushing the fish into the goalbox after $90 \mathrm{sec}$, but it should be noted that forcing did not become frequent until runway times had already increased. It is also likely that confinement in a small space is itself aversive. In any case, positive attractiveness of an empty goalbox, perhaps due to curiosity motivation, must attenuate very quickly.

A final point is that in the present experiment, effects produced by familiarity with the test environment were much less profound than those reported by Hogan (1974). The preexperimental screening procedure was probably partially responsible for the lack of effects of familiarity. This could be for two reasons: First, because subjects were selected for low emotionality, they may have been less reactive to an unfamiliar environment than fish used by Hogan. Second, because the apparatus used for screening was highly similar to the test apparatus, generalization effects may have overshadowed any effects of unfamiliarity. Therefore, if unfamiliarity produces effects by increasing fear level, as Hogan (1974) hypothesized, the lack of effects in the present study is understandable. However, the measures which were sensitive to familiarity (startbox latency and time motionless) do indicate that levels of fear were somewhat higher in the unfamiliar condition.

In conclusion, it follows from the preceding discussion that there is no simple explanation for the differential effects of aggressive display and food reinforcement on performance. The aversive component in aggressive display to a mirror can account for differences in asymptotic response levels and increased variability, but other factors are required to explain rapid extinction and failure to adjust response rates to ratio requirements. Still other factors are necessary to understand differences in performance for food, water, electrical stimulation of the brain, etc. (Hogan \& Roper, 1978). The most promising line of approach would seem to be identifying the various continua on which reinforcers vary, and investigating the effects of varying values on these continua for different reinforcers.

\section{REFERENCES}

BAENNINGER, R. Visual reinforcement, habituation, and prior social experience of Siamese fighting fish. Journal of Comparative and Physiological Psychology, 1970, 71, 1-5.

Bols, R. J. Display reinforcement in the Siamese fighting fish, Betta splendens: Aggressive motivation or curiosity? Journal of Comparative and Physiological Psychology, 1977, 91, 233-244.

Cotton, J. W. Running time as a function of amount of food deprivation. Journal of Experimental Psychology, 1953, 46, 188-198

Crespi, L. P. Quantitative variation of incentive and performance in the white rat. American Journal of Psychology, 1942, 55, 467-517.

Dore, F., Lefebvre, L., \& Ducharme, R. Threat display in Betta splendens: Effects of water condition and type of agonistic stimulation. Animal Behaviour, 1978, 26, 738-745.

Hinde, R. A. Animal Behavior: A synthesis of ethology and comparative psychology (2nd ed.). New York: McGraw-Hill, 1970.

Hogan, J. A. Fighting and reinforcement in the Siamese fighting fish (Betta splendens). Journal of Comparative and Physiological Psychology, 1967, 64, 356-359.

Hogan, J. A. On the choice between eating and aggressive display in the Siamese fighting fish (Betta splendens). Learning and Motivation, 1974, 5, 273-287.

Hogan, J. A., Ki.eist, S., \& Hutchings, C. S. L. Display and food as reinforcers in the Siamese fighting fish (Betta splendens). Journal of Comparative and Physiological Psychology, 1970. 70, 351-357.

Hotian, J. A., \& Ronk, T. J. A comparison of the properties 
of different reinforcers. Advances in the Study of Behavior, $1978,8,155-255$.

Ingersoll, D. W, Bronstein, P. M., \& Bonventre, J. Chemical modulation of agonistic display in Betta splendens. Journal of Comparative and Physiological Psychology, 1976, 90, 198-202.

K IRK, R. E. Experimental design: Procedures for the behavioral sciences. Belmont, Calif: Brooks/Cole, 1968.

Miller, N. E. Liberalization of basic S-R concepts: Extensions to conflict behavior, motivation, and social learning. In S. Koch (Ed.), Psychology: A study of a science (Vol. 2). New York: McGraw-Hill, 1959.

Morris, D. The function and causation of courtship ceremonies. In P. P. Grasse (Ed.), L'instinct dans le comportement des animaux et de l'homme. Paris: Fondation Singer Polignac, 1956.

Rhoad, K. E., Kalat, J. W., \& Klopfer, P. Aggression and and avoidance by Betto splendens toward natural and artificial stimuli. Animal Learning \& Behavior, 1975, 3, 271-276.
Sevenster, P. A causal analysis of a displacement activity (Fanning in Gasterosteus aculeatus L.). Behaviour, Supplement 9,1961 .

Simpson, M. J. A. The display of the Siamese fighting fish, Betta splendens. Animal Behavior Monographs, 1968, 1, 1-73.

Tinbergen, N. "Derived" activities; their causation, biological significance, origin and emancipation during evolution. Quarterly Review of Biology, 1952, 27, 1-32.

Young, P. T. Studies of food preference, appetite and dietary habit. VIII. Food-seeking drives, palatability and the law of effect. Journal of Comparative and Physiological Psychology, $1948,41,269-300$.

(Received for publication October 27, 1978; revision accepted February 16, 1979.) 